\title{
Previous hospital admissions and disease severity predict the use of antipsychotic combination treatment in patients with schizophrenia
}

\author{
Albert Bolstad ${ }^{1 *}$, Ole A Andreassen ${ }^{2,3}$, Jan I Røssberg ${ }^{2,3}$, Ingrid Agartz ${ }^{1,2}$, Ingrid Melle ${ }^{2,3}$ and Lars Tanum,
}

\begin{abstract}
Background: Although not recommended in treatment guidelines, previous studies have shown a frequent use of more than one antipsychotic agent among patients with schizophrenia. The main aims of the present study were to explore the antipsychotic treatment regimen among patients with schizophrenia in a catchment area-based sample and to investigate clinical characteristics associated with antipsychotic combination treatment.

Methods: The study included 329 patients diagnosed with schizophrenia using antipsychotic medication. Patients were recruited from all psychiatric hospitals in Oslo. Diagnoses were obtained by use of the Structured Clinical Interview for DSM-IV Axis I disorders (SCID-I). Additionally, Global Assessment of Functioning (GAF), Positive and Negative Syndrome Scale (PANSS) and number of hospitalisations and pharmacological treatment were assessed.

Results: Multiple hospital admissions, low GAF scores and high PANSS scores, were significantly associated with the prescription of combination treatment with two or more antipsychotics. The use of combination treatment increased significantly from the second hospital admission. Combination therapy was not significantly associated with age or gender. Regression models confirmed that an increasing number of hospital admission was the strongest predictor of the use of two or more antipsychotics.

Conclusions: Previous hospital admissions and disease severity measured by high PANSS scores and low GAF scores, predict the use of antipsychotic combination treatment in patients with schizophrenia. Future studies should further explore the use of antipsychotic drug treatment in clinical practice and partly based on such data establish more robust treatment guidelines for patients with persistently high symptom load.
\end{abstract}

\section{Background}

Evidence-based recommendations and guidelines for psychopharmacological treatment of schizophrenia are regarded as important tools to improve the quality of clinical treatment, to guide decision-making and to reduce inappropriate variations in clinical practice [1]. The guidelines also intended to offer a more rational treatment strategy and thereby optimizing the therapeutic efficacy and reduce the side effects [2-4]. Even so, prescriptions of antipsychotics have often deviated from expert recommendations [1,5], and treatment guidelines are not implemented for all schizophrenia patients [6,7]. Since up to $90 \%$ of patients with schizophrenia may be

\footnotetext{
* Correspondence: albert.bolstad@diakonsyk.no

'Department of Psychiatry Research, Diakonhjemmet Hospital, P.O. Box 85 Vinderen, Oslo 0319, Norway

Full list of author information is available at the end of the article
}

excluded from clinical trials, there will naturally be a gap between clinical practice and study reports on the efficacy of treatment [8]. The variation in prescription patterns across different regions and countries $[1,9,10]$ could also be due to differences in therapeutic traditions and treatment settings, attitudes towards antipsychotic drugs or cultural factors among psychiatrists.

It has been proposed that antipsychotic combination regimens are more frequently prescribed when the clinical course of the illness is complex or in treatmentresistant patients $[10,11]$. Studies of hospitalized patients with schizophrenia indicate a higher rate of antipsychotic combination treatment and use of First Generation Antipsychotics (FGA) compared to guideline recommendations $[10,12,13]$. Differences in prescription patterns could therefore be related to disease characteristics [1], although this has not yet been investigated in any 
catchment area sample representative of the majority of patients with schizophrenia.

The aim of this study was to explore the prescription pattern of antipsychotics among a sample of patients with schizophrenia receiving pharmacological treatment. The following research questions were addressed: 1 ) What types of antipsychotic medications are used in the treatment of schizophrenia in a Norwegian naturalistic catchment area sample? 2) Is the use of two or more antipsychotics associated with the severity of the disease as measured with the Global Assessment of Function (GAF), Positive and Negative Syndrome Scale (PANSS) and/or number of hospitalisations?

\section{Methods}

\section{Sample}

All the psychiatric hospitals in Oslo participate in the cross-sectional Thematically Organized Psychosis (TOP) Study, in which patients with psychotic disorders were recruited from outpatient as well as inpatient hospital units in a catchment area-based psychiatric service from 2003 to 2010 . Up to 2008 , we do not possess accurate data concerning out- or inpatient status at the time of inclusion in the study. A number of patients were recruited while being hospitalized, but actually included after discharge. The TOP study includes patients with a DSM-IV [14] diagnosis of schizophrenia and schizoaffective disorders, bipolar disorders and psychosis NOS. Patients were excluded if there was a previous history of head trauma, serious somatic illness or they were unable to give written, informed consent. For further information about the inclusion procedures, see [15-17]. A total of 329 patients, 213 (64.7\%) men and 116 (35.3\%) women, with schizophrenia fulfilled the inclusion criteria of the present study, including current use of antipsychotic medication and information on previous treatment history (For further patient characteristics, see Table 1).

The protocol was approved by The Norwegian Data Inspectorate and by the Regional Committee for Medical Research Ethics. All included patients received both written and oral information about the study and gave their written consent. The study was performed in full accordance with the Declaration of Helsinki (1965) and later revisions.

\section{Assessment}

All patients included in the study went through the Structured Clinical Interview for DSM-IV Axis I disorders (SCID-I) [18] for diagnostic purposes. All raters were investigators in the study, with a background either as medical doctor or clinical psychologist. The raters were trained in clinical interviews and assessments including video and case report ratings. Tests for rating reliability were performed for the different diagnoses, PANSS and GAF scores. The diagnostic reliability was found to be satisfactory with an overall agreement for DSM-IV diagnostic categories of $82 \%$ with $\kappa=0.77$ (95\% CI: 0.60-0.94). The level of functioning was assessed by use of the split version of the Global Assessment of Functioning scale (GAF) [18]. The GAF rating was carried out by the investigators, with a satisfactory inter-rater reliability for GAF-F (ICC $(1.1)=0.86$ ).

Relevant information on present and former drug treatment and previous hospitalisation were obtained from patient interviews and hospital records. If a patient used more than one antipsychotic drug at the time of the study, the drug prescribed in the highest dose, estimated from Defined Daily Doses (DDD), was defined as the primary therapeutic agent. If prescribed doses of two or more antipsychotics were equipotent, the medication with the longest duration was defined as the

Table 1 Background variables of patients included in the study $(\mathrm{n}=329 \#)$

\begin{tabular}{lll}
\hline & Mean (S.D) & Median (min. - max.) \\
\hline Age (years), $(n=329)$ & $31.9(9.6)$ & $30(17-60)$ \\
\hline Age of psychosis onset (years) $(n=140)$ & $23.8(8.3)$ & $22(7-54)$ \\
\hline Duration of untreated psychosis (weeks) $(n=142))$ & $134(182)$ & $76(0-1040)$ \\
\hline GAF-Symptom $(n=329)$ & $40.0(10.5)$ & $38(8-81)$ \\
\hline GAF-Function $(n=329)$ & $41.0(9.5)$ & $40(21-81)$ \\
\hline PANSS-positive $(n=305)$ & $16.3(5.9)$ & $16(7-32)$ \\
\hline PANSS-negative $(n=307)$ & $17.0(6.6)$ & $16(7-43)$ \\
\hline PANSS-general $(n=304)$ & $33.3(8.7)$ & $33(16-69)$ \\
\hline PANSS-total $(n=302)$ & $66.7(7.0)$ & $67(30-144)$ \\
\hline Previous hospital admissions $(n=329)$ & $3.5(5.3)$ & $2(0-40)$ \\
\hline
\end{tabular}

S.D.; standard deviation, GAF; Global Assessment of Functioning PANSS, Positive and Negative Syndrome Scale,

\# A total of 329 patients, 213 (64.7\%) men and 116 (35.3\%) women, with schizophrenia were included. Among these 261 (79.3\%) patients fulfilled the DSM-IV (16) criteria for the paranoid type of schizophrenia, 40 (12.2\%) patients undifferentiated type, $16(4.9 \%)$ disorganized type, $11(3.3 \%)$ residual type and $1(0.3 \%)$ catatonic type. 
primary therapeutic agent. Secondary and tertiary therapeutic agents were established in line with this.

\section{Statistical analysis}

Descriptive statistics was used for the initial analyses of frequencies, means and standard deviations (SD). Independent sample t-tests were used on between-group comparisons of means. Mann-Whitney test were used when skewed distribution of data were assumed. When dichotomous variables, we used Pearson Chi Square tests. Significant relationships were further explored by using a Backward Stepwise logistic regression model. Due to the low accuracy on the present inpatient versus outpatient treatment status, we did not include this factor in the logistic regression analyses. The effect sizes are presented as odds ratios. Nagelkerke's R-square was used to indicate goodness of fit. All analyses were performed using the Statistical Package for Social Sciences (SPSS), Version 14.

\section{Results}

A total of 329 patients received antipsychotic pharmacological treatment as their primary therapeutic medication. Out of these, 305 (92.7\%) patients received a second-generation antipsychotic (SGA) and 24 (7.3\%) patients received a first generation antipsychotic (FGA). Olanzapine was the most frequent used primary medication (31.6\%), followed by Quetiapine (17.6\%), Aripiprazol (15.5\%) and Risperidon (including Risperdal Consta) (12.4\%), (See Table 2).

A total of 101 (30.7\%) patients used two or more antipsychotics in combination. FGAs were used somewhat less frequent than SGAs (39 vs. 63 cases) as a second antipsychotic. Only 12 (3.2\%) of the patients used three or more antipsychotics. The combination of SGA + SGA was used in 61 patients, SGA+ FGA in 37 patients, FGA + FGA in only 2 patients and FGA + SGA were not used by any patient in this sample.

Patients using two or more antipsychotics scored on average significant lower on GAF-function and GAFsymptoms, while they scored significantly $(\mathrm{p}<0.05)$ higher on PANSS-positive symptom scale and PANSSnegative symptom scale. However, they did not score significantly higher on the PANSS-general symptom scale $(\mathrm{p}=0.056)$ and there was no association with age (See Table 3 and 4).

Number of previous admissions in the group of patients using only one antipsychotic drug was significantly lower than in the group of patients using two or more antipsychotic drugs (Mann-Whitney $U=8482,50$, $Z=-3.861, \mathrm{p}$-value $=0.000, \mathrm{r}=-0.2129)$. Duration of untreated psychosis (DUP) did not differ significantly between the groups (Mann-Whitney $U=1790.00, Z=$ $-1.134, p$ value $=0.257, \mathrm{r}=-0.0951)$.

Table 2 Received primary therapeutic agent (PTA) in the study population, $\mathbf{n}=\mathbf{3 2 9}$

\begin{tabular}{|c|c|c|c|}
\hline Drug or treatment regimen & No. of patients (\%) & Mean daily dose $\mathrm{mg}^{*}$ & CPZ equivalents $\mathrm{mg}^{* *}$ \\
\hline Second generation antipsychotic (SGA) & $305(92.7 \%)$ & & \\
\hline Olanzapine & $104(31.6 \%)$ & 14.4 & 288 \\
\hline Risperidon or Risperdal Consta & $41(20.6 \%)$ & 3.7 & 244 \\
\hline Quetiapine & $58(17.6 \%)$ & 537,5 & 698 \\
\hline Aripiprazole & $51(15.5 \%)$ & 14.2 & 189 \\
\hline Ziprasidon & $20(6.1 \%)$ & 85.8 & 137 \\
\hline Amisulpride & $11(3.3 \%)$ & 615.9 & 616 \\
\hline Clozapine & $16(4.8 \%)$ & 390.6 & 391 \\
\hline Sertindole & $4(1.2 \%)$ & 18.2 & 342 \\
\hline First generation antipsychotic (FGA) & $24(7.3 \%)$ & & \\
\hline Perphenazine or Perphenazine decan. & $12(3.6 \%)$ & 8.9 & 111 \\
\hline Zuclopenthixol or Zuclopenthixol decan. & $6(2.1 \%)$ & 20.0 & 80 \\
\hline Chlorprothixen & $3(0.9 \%)$ & 116.7 & 233 \\
\hline Levomepromazine & $1(0,3 \%)$ & 120 & 120 \\
\hline Chlorpromazine & $1(0.3 \%)$ & 30.0 & 120 \\
\hline Flupentixol & $1(0.3 \%)$ & 1.0 & 50 \\
\hline Haloperidol & $0(0 \%)$ & & \\
\hline No. of patients using only one antipsychotic drug & $228(69.3 \%)$ & & \\
\hline No. of patients using more than one antipsychotic drug & $101(30.7 \%)$ & & \\
\hline
\end{tabular}

*Per oral medication only.

** CPZ equivalents; Chlorpromazine equivalents according to Kroken et al 2009: http://www.biomedcentral.com/1471-244X/9/24/table/T1 
Table 3 Group wise comparing of means

\begin{tabular}{lll}
\hline & Patients with one antipsychotic & Patients with two or more antipsychotics \\
\hline Age $(n=329)$ & Mean & Mean \\
\hline Age at onset of psychosis $(n=140)$ & 32.12 & 31.32 \\
\hline Duration (weeks) of untreated psychosis $(n=142)$ & 24.11 & 23.06 \\
\hline GAF-S $(n=329)$ & 151 & 91 \\
\hline GAF-F $(n=329)$ & 41.51 & 36.65 \\
\hline PANSS-positive $(n=305)$ & 42.32 & 38.15 \\
\hline PANSS negative $(n=307)$ & 15.81 & 17.38 \\
\hline PANSS general $(n=304)$ & 16.16 & 18.82 \\
\hline PANSS total $(n=302)$ & 32.75 & 34.82 \\
\hline Number of previous admissions $(n=329)$ & 64.65 & 71.29 \\
\hline
\end{tabular}

GAF-S; Global Assessment of Functioning,-Symptom, GAF-F Global Assessment of Functioning, - Functions, PANSS; Positive and Negative Syndrome Scale

Pearson Chi-Square showed a significant relationship between two or more previous admissions and antipsychotic combination treatment (Value 9.086; Asymp. pvalue $=0.003)$.

However, Pearson Chi-Square did not show any significant relationship between gender and antipsychotic combination treatment (Value 0.009; Asymp. $\mathrm{p}$-value = 0.922). We have information on inpatient versus outpatient status in only 161 out of 329 patients. Only 12 (16.7\%) out of 72 outpatients received antipsychotic combination treatment while 33 (37.1\%) out of 89 inpatients at the time of inclusion received antipsychotic combination treatment. We found a significant relationship between inpatient status and antipsychotic combination treatment (Pearson Chi-Square Value 9.045; Asymp. p-value $=0.003)$.
As displayed in Table 5, the probability of two or more antipsychotics being used increased with the number of previous admissions to a psychiatric hospital. Among patients with two or more previous admissions, $36.8 \%$ received combination treatment. In contrast, only $21.9 \%$ of the patients with one or no previous admissions, and only $18.4 \%$ of patients not previously admitted, received such treatment. There was a nominal increase in patients receiving two or more antipsychotics up to the fourth previous admission. However, the portion of patients receiving two or more antipsychotics did not further increase with higher numbers of previous admissions. We used a stepwise backward logistic regression model exploring the individual strength of the possible predictors. We entered GAF-symptom, GAF-function, PANSS-positive, PANSS-negative,

Table 4 Independent sample t-test comparing group of patients with one antipsychotic versus patients with two or more antipsychotics

\begin{tabular}{llll}
\hline & T-test for equality of means & \\
\hline & $\mathbf{t}$ & Sig (2-tailed) & $\begin{array}{l}\mathbf{9 5 \%} \text { Confidence for the difference } \\
\text { Lower - Upper }\end{array}$ \\
\hline Age $(n=329)$ & 0.689 & 0.486 & $-1.457-3.060$ \\
\hline Age at onset of psychosis $(n=140)$ & $0.795^{*}$ & 0.429 & $-1.583-3.692$ \\
\hline Duration $($ weeks) of untreated psychosis $(n=142)$ & $2.318^{*}$ & 0.022 & $8.757-110.567$ \\
\hline GAF-S $(n=329)$ & 3.971 & 0.000 & $2.452-7.267$ \\
\hline GAF-F $(n=329)$ & 3.734 & 0.000 & $1.972-3.363$ \\
\hline PANSS-positive $(n=305)$ & -2.187 & 0.030 & $-2.997--0.158$ \\
\hline PANSS negative $(n=307)$ & -3.297 & 0.001 & $-4.239--1.070$ \\
\hline PANSS general $(n=304)$ & -1.916 & 0.056 & $-4.195--0.056$ \\
\hline PANSS total $(n=302)$ & -3.133 & 0.002 & $-10.821--2.471$ \\
\hline Number of previous admissions $(n=329)$ & $-2.859^{*}$ & 0.005 & $-3.323--0.606$ \\
\hline No. of previous admission dichotomized, & $-3.189^{*}$ & 0.002 & $-0.284--0.067$ \\
\hline 0 or 1 vs. 2 or more previous admissions) & & & \\
\hline * Equal variances not assumed due to Levene's Test for Equality of Variances, $p<0.05$ &
\end{tabular}

* Equal variances not assumed due to Levene's Test for Equality of Variances, $\mathrm{p}<0.05$ 
Table 5 Number of previous hospital admissions; comparison of patients with only one antipsychotic versus patients with two or more antipsychotics

\begin{tabular}{|c|c|c|c|c|c|c|c|c|c|c|}
\hline & & \multicolumn{9}{|c|}{ No. of previous admissions to psychiatric ward } \\
\hline & & 0 & 1 & 2 & 3 & 4 & 5 & 6 & 7 & $8+$ \\
\hline & $N=329$ & 49 & 79 & 63 & 39 & 29 & 14 & 13 & 13 & 30 \\
\hline One antipsychotic & $\begin{array}{l}228 \\
(69.3 \%)\end{array}$ & $\begin{array}{l}40 \\
(81.6 \%)\end{array}$ & $\begin{array}{l}61 \\
(77.2 \%)\end{array}$ & $\begin{array}{l}46 \\
(73.0 \%)\end{array}$ & $\begin{array}{l}28 \\
(71,8 \%)\end{array}$ & $\begin{array}{l}13 \\
(44.8 \%)\end{array}$ & $\begin{array}{l}8 \\
(57.1 \%)\end{array}$ & $\begin{array}{l}8 \\
(44.8 \%)\end{array}$ & $\begin{array}{l}8 \\
(61.5 \%)\end{array}$ & $\begin{array}{l}16 \\
(53.3 \%) \\
\end{array}$ \\
\hline Two or more antipsychotics & $\begin{array}{l}91 \\
(30.7 \%)\end{array}$ & $\begin{array}{l}9 \\
(18.4 \%)\end{array}$ & $\begin{array}{l}18 \\
(22.8 \%)\end{array}$ & $\begin{array}{l}17 \\
(27.0 \%)\end{array}$ & $\begin{array}{l}11 \\
(28.2 \%)\end{array}$ & $\begin{array}{l}16 \\
(55.2 \%)\end{array}$ & $\begin{array}{l}6 \\
(42.9 \%)\end{array}$ & $\begin{array}{l}5 \\
(38.5 \%)\end{array}$ & $\begin{array}{l}5 \\
(38.5 \%)\end{array}$ & $\begin{array}{l}14 \\
(46.7 \%)\end{array}$ \\
\hline
\end{tabular}

PANSS-general sub score and previous admissions into the regression model. The number of previous admissions was dichotomized into two groups, less than two admissions versus two or more admissions. Two or more previous hospital admissions appeared to be the far strongest predictor of combination treatment, followed by a low GAF symptoms score and a high PANSS-negative symptoms score (Table 6) The group of patients with two or more previous admissions showed an odds ratio of 2.445 , for receiving two or more antipsychotics compared to patients with no or one previous admissions. Nagelkerkes R Square was 0.135 for the last step.

\section{Discussion}

The main finding of this study is that the prevalence of antipsychotic combination treatment increased with number of hospital admissions, severity of the disease as measured with PANSS, and level of dysfunction, as measured with GAF. The current finding that previous hospital admissions were related to antipsychotic combination treatment is in line with Kroken el. al [9] who found that in-patient treatment in the previous 12 months predicted polypharmacy. As seen from table 5, increase in number of hospital admissions beyond four did not seem to increase to probability of receiving two or more antipsychotics. We dichotomized the sample and chose a cut-off between one and two previous admissions. The reason for choosing this cut-off value was primarily the clinical relevant distinction between patients who were readmitted and those who were not. In a number of the patients first admittance to hospital was not necessarily due to problems with ongoing treatment, but due to a more acute or dramatic onset of symptoms of schizophrenia. Choosing a cut-off between one and two admissions therefore reflects to a greater extend patients with poor compliance or lack of response to ongoing treatment.

The cut-off points could just as well have been set between two and three, or between three and four previous admissions, providing slightly higher odds ratios. However, more than five previous admissions did not further increase the probability of receiving an antipsychotic combination treatment. Our results seem to be in line with studies that suggest a combination of antipsychotics as an option in non-responders with a higher degree of relapse, or in patients with more severe schizophrenia $[5,12,19,20]$. The finding that the use of antipsychotics were mainly in accordance with guidelines up to the second admission to hospital, supports the hypothesis that antipsychotic combination therapy is more likely to be prescribed when treatment according to guidelines has not achieved an adequate therapeutic response.

Previous studies have not reported any significant correlation between prescription pattern and decline in global- or daily functioning, measured with GAF $[9,21]$. This could be due to a type II error, at least in one of the studies, since this only included inpatients [9]. The current finding of PANSS score versus combination treatment, has not been reported earlier. A higher level of current psychotic symptoms, as measured with total PANSS scores, further supports the hypothesis that antipsychotic combination therapy is more likely to be prescribed when guideline treatments have not achieved an adequate therapeutic response.

Table 6 Logistic regression model; Backward Stepwise (Wald) Previous admissions dichotomized 0-1 versus 2 or more

\begin{tabular}{lllll}
\hline Patient factor & Odds Ratio (Exp.(B)) & $\begin{array}{l}\mathbf{9 5 . 0 \% ~ C . I . ~ f o r ~ O R ~} \\
\text { Lower - Upper }\end{array}$ & P-value & Wald \\
\hline Step 4 (last step) ${ }^{*}$ & & & & \\
\hline GAF-Symptom & 0.953 & $0.924-0.983$ & 0.002 & 9.239 \\
\hline PANSS-negative symptoms & 1,048 & $1.007-1.090$ & 0.022 & 5.242 \\
\hline Two or more hospital admissions & 2.445 & $1.416-4.225$ & 0.001 & 10.258 \\
\hline
\end{tabular}

GAF; Global Assessment of Functioning, PANSS; Positive and Negative Syndrome Scale, OR; Odds Ratio

*Nagelkerke R Square $=0.135$ 
Our naturalistic sample of patients consisting of both inpatients and outpatients at the time of the examination, might be more representative for the population of patients with schizophrenia at various stages of the illness, providing a relatively wide spectrum in symptom levels and functioning and thus GAF and PANSS scores. This probably enabled us to detect important associations that are difficult to find in more selected groups of patients e.g. inpatients only.

Duration of untreated psychosis (DUP) was verified in only a portion of the patients but did not show any significant relationship to combination treatment with antipsychotics. This may be in line with our finding that age did not show any significant relationship with such treatment either. Future studies should further explore the role of DUP with regard to medication regimens.

The overall rate of antipsychotic combination treatment among our patients was comparable to other naturalistic studies $[9,12]$. In our study SGAs were used more frequently as the preferred antipsychotic drug than reported from some European studies performed during the same time period $[9,11,22,23]$, but was in line with other study reports [24]. The use of FGA as a primary therapeutic agent was relatively infrequent in our study. The variation in prescription patterns of SGAs may be attributed to both guideline adherence and how the public health systems work in different countries, including to what extent prescriptions of all antipsychotic medications are reimbursed by the social security program, as well as differences in the hospitals' financial schemes which influence the choice of low-versus high-cost medications.

Evidence-based guidelines for the psychopharmacological treatment of schizophrenia are important for securing a high quality of clinical practice including rational strategies to minimize adverse effects. However, the knowledge is rather scarce on how to guide treatment decisions in non-responders to antipsychotic monotherapy, which may be reflected by the lack of evidence-based recommendations for this group of schizophrenia patients. A better discrimination between subgroups of patients with different clinical courses of the illness is therefore needed when proposing new recommendations, moving today's guidelines with their "one size fits all" approach to antipsychotic medications closer to clinical practice.

The current body of evidence to support a combination of two or more antipsychotics in schizophrenia is not conclusive [20,24-26], even though antipsychotic combination treatment may be superior to monotherapy in a limited number of patients [12,26,27]. A few randomized controlled trials have reported treatment with clozapine in combination with a second antipsychotic, to be superior to clozapine in monotherapy in subgroups of patients [27].

The current study involved all psychiatric hospitals in Oslo and included both in- and outpatients. The public health care service in Norway is good and provides adequate treatment for all psychiatric patients. There is no privately financed health care that offers long-term treatment for patients with schizophrenia, which enabled us to collect representative data on current treatment with a rather low degree of selection bias.

\section{Limitations}

Our data are based on a sample of cooperating patients who agreed to join the study, including all assessments and interviews. Many patients were outpatients, indicating a higher degree of treatment compliance compared to inpatients or long-term hospitalized patients. In contrast, studies that only recruit inpatients may have a selection bias towards more severe and treatment-refractory cases.

\section{Conclusions}

Patients with previous hospital admissions and disease severity measured by high PANSS scores and low GAF scores were more likely to receive an antipsychotic combination treatment. Future studies should further explore the use of antipsychotic drug treatment in clinical practice and partly based on such data establish more robust treatment guidelines for patients with persistently high symptom load.

\section{Abbreviations \\ DDD: Defined Daily Doses; FGA: First Generation Antipsychotic; SGA: Second Generation Antipsychotics; GAF-F: Global Assessment of Functioning; SCID-I: The Structured Clinical Interview for DSM-IV; PANSS: Positive and Negative Syndrome Scale; DUP: Duration of Untreated Psychosis; TOP: Thematically Organized Psychosis;}

\section{Acknowledgements}

The authors wish to thank the participants for their time and essential contribution to the study, and the TOP study group members for their participation in the data collection. This work was supported by: South East Norway Health Authority (\# 2004-123) and the Research Council of Norway (\# 167153), with support from the University of Oslo to the TOP study group.

\section{Author details}

${ }^{1}$ Department of Psychiatry Research, Diakonhjemmet Hospital, P.O. Box 85 Vinderen, Oslo 0319, Norway. ${ }^{2}$ Section of Psychosis Research, Clinic of Mental Health and Addiction, Oslo University Hospital, Ullevål Hospital, P.O. Box 4956 Nydalen, Oslo 0424, Norway. ${ }^{3}$ Institute of Clinical Medicine, University of Oslo, P.O. Box 1171 Blindern, Oslo 0318, Norway. ${ }^{4}$ Department of Psychiatric Research and Development, Akershus University Hospital and University of Oslo, Lørenskog 1478, Norway.

\section{Authors' contributions}

$\mathrm{AB}$ : collecting data, analysis, drafting and revising the manuscript. OAA: conception of the study, collecting data, analysis, drafting and revising the manuscript. JIR: conception of the study and revising the manuscript. IA: conception of the study, collecting data and revising the manuscript. IM: 
conception of the study, collecting data and revising the manuscript. LT: conception of the study, analysis, drafting and revising the manuscript. All authors have read and approved the final manuscript.

\section{Competing interests}

OAA and LT have received a speaker's honorarium from Astra-Zeneca, GlaxoSmithKline, Janssen-Cilag and Bristol Myers Squibb. LT has also received a speaker's honorarium from Sanofi-Aventis. IM have received a speaker's honorarium from Astra-Zeneca, Eli-Lilly, Janssen-Cilag and Lundbeck. IA is an unpaid consultant to Eli Lilly. No competing interests.

Received: 10 September 2010 Accepted: 3 August 2011

Published: 3 August 2011

\section{References}

1. Owen RR, Fisher EP, Kirchner JE, Thrust CR, Williams K, Cuffel BJ, et al: Clinical Practice Variations in Prescribing Antipsychotics for Patients with Schizophrenia. Am J Medical Quality 2003, 18(4):140-145.

2. National Institute for Health and Clinical Excellence: Schizophrenia, Core interventions in the treatment and management of schizophrenia in adults in primary and secondary care. NICE, (UK) 2002.

3. Lehman AF, Lieberman JA, Dixon LB, McGlashan TH, Miller AL, Perkins DO, Kreyenbuhl J: Practice guidelines for the treatment of patients with schizophrenia. Am J Psychiatry, Second 2004, 16(2 Suppl):1-56.

4. Lehman AF, Kreyenbuhl J, Buchanan RW, Dickerson FB, Dixon LB, Goldberg R, et al: The Schizophrenia Patient Outcomes Research Team (PORT): Updated Treatment Recommendations 2003. SchizophrBull 2004, 30(2):193-217.

5. Wolff-Menzler C, Hasan A, Malchow B, Falkai P, Wobrock T: Combination Therapy in the Treatment of Schizophrenia. Pharmacopsychiatry 2010, 43:122-129.

6. Weinmann $\mathrm{S}$, Koesters $\mathrm{M}$, Becker $\mathrm{T}$ : Effects of implementation of psychiatric guidelines on provider performance and patient outcome: a systematic review. Acta Psychiatr Scand 2007, 115:420-433.

7. Leucht S: Psychiatric treatment guidelines: doctors' non-compliance or insufficient evidence? Acta Psychiatr Scand 2007, 115:417-419.

8. Leucht S, Heres S, Hamann J, Kane JM: Methodological Issues in Current Antipsychotic Trials. Schizophr Bull 2008, 34:275-285.

9. Young AS, Sullivan G, Burnam MA, Brook RH: Measuring the Quality of Outpatient Treatment for Schizophrenia. Arch Gen Psychiatry 1998, 55:611-617.

10. Kroken R, Johnsen E, Ruud T, Wentzel-Larsen T, Jorgensen HA: Treatment of schizophrenia with antipsychotics in Norwegian emergency wards, a cross-sectional national study. BMC Psychiatry 2009.

11. Weinmann S, Janssen B, Gaebel W: Guideline adherence in medication management of psychotic disorders: an observational multisite hospital study. Acta Psychiatr Scand 2005, 11:18-25.

12. Johnsen E, Svingen GF, Jørgensen HA: Practice regarding antipsychotic therapy: A cross-sectional survey into Norwegian hospitals. Nord J Psychiatry 2004, 58:313-317.

13. Patrick V, Schleifer SJ, Nurenberg JR, Gill KJ: An Initiative to Curtail the Use of Antipsychotic Polypharmacy in a State Psychiatric Hospital. Psychiat Serv 2006, 57:21-23.

14. American Psychiatric Association: Diagnostic and Statistical Manual of Mental Disorders DSM-IV. American Psychiatric Association, Washington DC i, 41994.

15. Ringen $P A$, Melle I, Birkeneaes $A B$, Engh JA, Faerden $A$, Vaskin $A$, et al: The level of illicit drug use is related to symptoms and premorbid functioning in severe mental illness. Acta Psychiatric Scand 2008, 118:297-304.

16. Birkenaes AB, Søgaard AJ, Engh JA, Jonsdottir H, Ringen A, Vaskin A, et al: Sociodemographic Characteristics and Cardiovascular Risk Factors in Patients with Severe Mental Disorders Compared With the General Population. J Clin Psychiatry 2006, 67:425-433.

17. Jònsdòttir $H$, Opjordsmoen $S$, Birkenaes $A B$, Engh JA, Ringen $P A$, Vaskin $A$, et al: Medication adherence in outpatients with severe mental disorders: Relation between self-reports and serum-level. Journal of Clinical Psychopharmacology 2010, 30:169-175.

18. First MB, Spitzer RL, Gibbon M: Structured Clinical Interview for DSM-IV Axis I Disorders-Patient Edition (SCID I/P, version 2.0). New York: New York State Psychiatric Institute, Biometrics Research Dept; 1995.
19. Pedersen G, Hagtvedt KA, Karterud S: Generalizability studies of the Global Assessment of Functioning-Split version. Compr Psychiatry 2007, 48(1):88-94.

20. Falkai P, Wobrock T, Lieberman J, Glenthoj B, Gattaz WF, Möller HJ, WFSBP Task Force on Treatment Guidelines for Schizophrenia: WFSBP- guidelines for biological treatment of schizophrenia part -2. Long-term treatment of schizophrenia. World J Biol Psychiatry 2006.

21. Goodwin G, Fleischhacker W, Arango C, Baumann P, Davidson M, de Hert $M$, et al: Advantages and disadvantages of combination treatment with antipsychotics. ECNP Consensus Meeting, March 2008. Eur Neuropsychopharmacology 2009, 19:520-532.

22. Kreyenbuhl JA, Valenstein M, McCarty JF, Granoczy D, Blow FC: Long-Term Antipsychotic Polypharmacy in the VA health system: patient characteristics and treatment patterns. Psychiatr Serv 2007, 58:489-495.

23. Ballerini A, Baccalon RM, Boncompagni G, Casacchia M, Margari F, Minervini $L$, et al: Main clinical features in patients at their first psychiatric admission to Italian acute hospital psychiatric wards. The PERSEO study. BMC Psychiatry 2007, 7:3.

24. Lieberman JA, Stroup TS, McEvoy JP, Swartz MS, Rosenheck RA, Perkins DO, et al: Clinical Antipsychotic Trials of Intervention Effectiveness (CATIE) Investigators. Effectiveness of antipsychotic drugs in patients with chronic schizophrenia. New Engl J Med 2005, 353(12):1209-1223.

25. Stahl SM, Grady MM: A critical review of atypical antipsychotic utilization: - comparing monotherapy with polypharmacy and augmentation. Curr Medicinal Chemistry 2004, 11:313-327.

26. Tranulis C, Skalli L, Lalonde P, Nicole L, Stip E: Benefit and Risk of Antipsychotic Polypharmacy. An Evidence-Based Review of the Literature. Drug Safety 2008, 31:7-20.

27. Correll CU, Rummel-Kluge C, Corves C, Kane JM, Leucht S: Antipsychotic Combinations vs. Monotherapy in Schizophrenia: A Meta-analysis of Randomized Controlled Trials. Schizophr Bull 2009, 35:443-457.

\section{Pre-publication history}

The pre-publication history for this paper can be accessed here: http://www.biomedcentral.com/1471-244X/11/126/prepub

doi:10.1186/1471-244X-11-126

Cite this article as: Bolstad et al:: Previous hospital admissions and disease severity predict the use of antipsychotic combination treatment in patients with schizophrenia. BMC Psychiatry 2011 11:126.

\section{Submit your next manuscript to BioMed Central and take full advantage of:}

- Convenient online submission

- Thorough peer review

- No space constraints or color figure charges

- Immediate publication on acceptance

- Inclusion in PubMed, CAS, Scopus and Google Scholar

- Research which is freely available for redistribution

Submit your manuscript at www.biomedcentral.com/submit
C Biomed Central 